Research Paper

\title{
Utilization of leukapheresis and CD4 positive selection in Treg isolation and the ex-vivo expansion for a clinical application in transplantation and autoimmune disorders
}

\author{
Karolina Gołąb ${ }^{1}$, Randall Grose ${ }^{2}$, Piotr Trzonkowski ${ }^{3}$, Amittha Wickrema ${ }^{4}$, Martin \\ Tibudan $^{1}$, Natalia Marek-Trzonkowska ${ }^{5}$, Sabrina Matosz ${ }^{1}$, Julia Solomina ${ }^{1}$, Diane \\ Ostrega ${ }^{1}$, J. Michael Millis ${ }^{1}$, Piotr Witkowski ${ }^{1}$ \\ ${ }^{1}$ Department of Surgery, Section of Transplantation, University of Chicago, Chicago, USA \\ ${ }^{2}$ South Australian Health and Medical Research Institute, University of Adelaide, Australia \\ ${ }^{3}$ Department of Clinical Immunology and Transplantology, Medical University of Gdansk, Gdansk, Poland \\ ${ }^{4}$ Department of Medicine, Section of Hematology-Oncology, Cancer Research Center, University of Chicago, Chicago, USA \\ ${ }^{5}$ Department of Family Medicine, Medical University of Gdansk, Gdansk, Poland
}

Correspondence to: Piotr Witkowski, email: pwitkowski@surgery.bsd.uchicago.edu

Keywords: regulatory $T$ cells, clinical application, leukapheresis, CD4+ cells, immunosupressive therapy

Received: January 27, $2016 \quad$ Accepted: October 26, 2016

Published: November 04, 2016

\section{ABSTRACT}

Adoptive transfer of $\mathrm{T}$ regulatory cells (Tregs) is of great interest as a novel immunosuppressive therapy in autoimmune disorders and transplantation. Obtaining a sufficient number of stable and functional Tregs generated according to current Good Manufacturing Practice (cGMP) requirements has been a major challenge in introducing Tregs as a clinical therapy. Here, we present a protocol involving leukapheresis and $\mathrm{CD4}^{+}$cell pre-enrichment prior to Treg sorting, which allows a sufficient number of Tregs for a clinical application to be obtained. With this method there is a decreased requirement for ex-vivo expansion. The protocol was validated in cGMP conditions. Our final Treg product passed all release criteria set for clinical applications. Moreover, during expansion Tregs presented their stable phenotype: percentage of $\mathrm{CD}^{+}{ }^{+} \mathrm{CD} 25^{\mathrm{hi}} \mathrm{CD} 127^{-}$and $\mathrm{CD}^{+}{ }^{+}$FoxP3 ${ }^{+}$Tregs was $>95 \%$ and $>80 \%$, respectively, and Tregs maintained proper immune suppressive function in vitro. Our results suggest that utilization of leukapheresis and CD4 positive selection during Treg isolation improves the likelihood of obtaining a sufficient number of high quality Treg cells during subsequent ex-vivo expansion and they can be applied clinically.

\section{INTRODUCTION}

$\mathrm{T}$ regulatory cells (Tregs) have ability to regulate immune reaction and maintain self-tolerance attenuating autoimmunity, allergy, pathogen-induced immunopathology and over-exuberant immune responses [1-4]. Due to their properties, Tregs are favorable for therapeutic tools in tolerance restoration/ induction in autoimmunity disorders and in cell/solid organ transplantation, however a high number of cells are required to obtain clinical effects [5]. Therefore, the strategy for clinical applications of the Tregs involves their isolation and ex vivo expansion followed by the infusion into a patient. After successful Treg application in pre-clinical models, first clinical trials with Tregs were conducted in graft-versus-host disease (GvHD) after bone marrow transplantation [6-9] as well as in new onset of type 1 Diabetes Mellitus (T1DM) [10-12]. Several new clinical trials with Tregs are ongoing in solid organ transplantation and other immune disorders [13, 14].

Nevertheless many aspects of clinical application of Tregs as immunotherapy still remain challenging. Tregs are not a homogenous cell population and at least two main subpopulations are distinguished: natural, thymic Tregs (tTregs) and induced or adaptive Tregs (aTregs) $[15,16]$. tTregs are generated in the thymus and express high levels of CD25 and lineage marker FoxP3 (forkhead transcription factor box P3) [17], whereas aTregs are generated in periphery upon contact with antigen from $\mathrm{CD} 4^{+} \mathrm{CD} 25^{-}$ precursors [18]. Moreover, most of the single surface markers that are used for defining Tregs (like FoxP3) are not exclusively Treg-specific and upon certain conditions 
can be expressed on activated conventional Th cells [1]. That complicates Treg identification during the isolation and quality check of the final product before clinical application. In our work, we focused on ex vivo expansion of polyclonal tTregs, which exhibit in vivo and in vitro stable regulatory function. Those Tregs can be identified as cells with the phenotype: $\mathrm{CD} 4^{+} \mathrm{CD} 25^{\text {high }} \mathrm{CD} 127-\mathrm{FoxP}^{+}$ and are also characterized by stable methylation status of TSDR (Treg-Specific Demethylated Region) in the FoxP3 gene [19-21]. Isolation of Tregs can be done via immunomagnetic bead separation or fluorescenceactivated cell sorting (FACS), or by combination of both these methods. Immunomagnetic isolation, despite being more robust, is less accurate and does not provide the ability to select as pure and as precisely defined Treg population as the sorting technique $[22,23]$.

Most approaches utilize the patient's own peripheral blood as a source of Tregs. Alternatively, umbilical cord blood (UCB) could be used, but so far a minority of the patients have banked UCB. Isolated Tregs need to be expanded in vitro due to low number and frequency in the blood. Treg proliferation is usually induced by T-cell receptor (TCR) stimulation. Microbeads covered with anti-CD3/CD28 antibodies can be used for such stimulation after which Tregs are expanded in the presence of recombinant human interleukin-2 (IL-2) $[6,10,23,24]$. The number of Treg cells that could be obtained after expansion often varies. Donor age is only one example of many factors which can affect fold of expansion $[10,25,26]$. Even despite optimized expansion protocol (culture conditions and time), lower starting with numbers of Tregs requires higher fold increase during expansion to generate sufficient final number of Tregs for clinical application, which leads to higher risk of failure [26]. As increasing blood drawing volume to obtain higher starting Treg number is impractical, we decided to utilize leukapheresis for initial Treg cell retrieval. Such modification allowed isolating much higher Treg numbers limiting the risk of achieving insufficient Treg final numbers after the expansion. Leukapheresis product has been tested previously in other protocols for Treg isolation. However, in these protocols Tregs were not subsequent expanded or isolated via immunomagnetic beads separation $[27,28]$. In our protocol, we utilized leukapheresis in combination with $\mathrm{CD}^{+}$positive magnetic selection (pre-enrichment) and FACS sorting for enhanced purity and number of Tregs.

To utilize Treg-based therapy in clinical settings, cell processing must be performed according to current Good Manufacturing Practice (cGMP) guidelines, which ensures product quality, limiting the risk of cross-contamination and pathogenic transmission [29]. Additionally, as the United States law (21 CFR $\S 1271$ ) states, the Food and Drug Administration (FDA) requires cell-based product to be tested and documented for sterility, identity, purity and potency before it can be administered into a patient. That requires passing an array of tests meeting final release criteria before the final Treg product can be safely released for a clinical use.

Here, we present validation of our Treg production protocol that we established according to cGMP guidelines and FDA requirements for cell-based products. Before establishing the final clinical-grade protocol, we performed several research-grade Treg isolations/ expansions to optimize and ensure the best conditions for Treg processing [30]. After that, to check the feasibility of our established protocol, we performed several more pre-clinical grade Treg isolations and expansions, and we present the results here. In the final step, we validated the protocol in the cGMP settings with the use of all clinicalgrade reagents. All together, we show below that we can provide in consistent manner, sterile, well-defined Treg cell final product to be considered by FDA for Investigational New Drug (IND) approval and to be tested for safety and effectiveness in clinical studies.

\section{RESULTS}

\section{Pre-clinical grade Treg isolations and expansions}

For Treg isolations we used leukapheresis product obtained from healthy donors that contained according to the provider, $6 \times 10^{9}-10 \times 10^{9}$ peripheral blood mononuclear cells (PBMCs). Our phenotype analysis showed that in PBMCs, $35 \pm 9.3 \%$ cells were CD4 positive and $5.8 \pm 0.3 \%$ of those cells expressed Treg markers $\left(\mathrm{CD} 4^{+} \mathrm{CD} 25^{\text {hi }} \mathrm{CD} 127^{-/ \mathrm{lo}}\right)$. After immunomagnetic $\mathrm{CD}^{+}$ cells isolation on CliniMACS ${ }^{\circledR}$ device, we achieved 1.9 $\times 10^{9} \pm 7.8 \times 10^{8} \mathrm{CD}^{+}$cells with purity of $99.2 \pm 0.3 \%$, viability of $93 \pm 8.4 \%$ and containing $6 \pm 0.1 \%$ Tregs $\left(\mathrm{CD} 4^{+} \mathrm{CD} 25^{\text {hi }} \mathrm{CD} 127^{-/ \mathrm{lo}}\right.$ cells). Only a portion of those cells were used for further processing, whereas remaining parts were cryopreserved for future use. Similarly, only a part of subsequently isolated $\mathrm{CD}^{+}$cells were sorted thus obtaining pure Tregs, which were next expanded, according to described below clinical-grade 13 day expansion protocol with average 176.7 fold increase in Treg number (Figure 1A). During expansion, Tregs maintained stable phenotype - \% of cells with expression $\mathrm{CD} 4{ }^{+} \mathrm{CD} 25^{\text {hi }} \mathrm{CD} 127^{-1 \mathrm{lo}}$ was $>95 \%$ and with $\mathrm{CD}^{+} \mathrm{FoxP}^{+}>$ $85 \%$ at all expansion checkpoints (Figure 1B). Expanded Tregs also demonstrated good suppressive abilities in in vitro suppression of proliferation assay (Figure 1C).

\section{Validation of clinical-grade Treg isolation and expansion protocol}

For clinical-grade validation of Treg isolation and expansion protocol we obtained leukapheresis product from the same provider. Accordingly to our phenotype analysis $55.2 \%$ of PBMCs were $\mathrm{CD} 4^{+}$positive and $8 \%$ of them were $\mathrm{CD} 4^{+} \mathrm{CD} 25^{\mathrm{hi}} \mathrm{CD} 127^{-1 \mathrm{lo}}$. $\mathrm{CD} 4^{+}$cells were 
isolated in the number of $1.6 \times 10^{9}$ with the purity of $98.9 \%$, viability of $94 \%$ and they contained $8.1 \%$ Tregs $\left(\mathrm{CD} 4{ }^{+} \mathrm{CD} 25^{\text {hi }} \mathrm{CD} 127^{-/ 10}\right.$ cells). Sorting of $5 \times 10^{8}$ of $\mathrm{CD}^{+}$cells allowed us to obtain $9.7 \times 10^{6}$ of Tregs with the purity $97.4 \%$ and $77.9 \%$ measured by $\%$ of cells expressing $\mathrm{CD}^{+} \mathrm{CD} 25^{\mathrm{hi}} \mathrm{CD} 127^{-/ \mathrm{lo}}$ and $\mathrm{CD} 4^{+} \mathrm{FoxP}^{+}$, respectively (Figure 2A). Sorted Tregs were characterized by good viability $(88.6 \%)$ and sterility based on negative

A

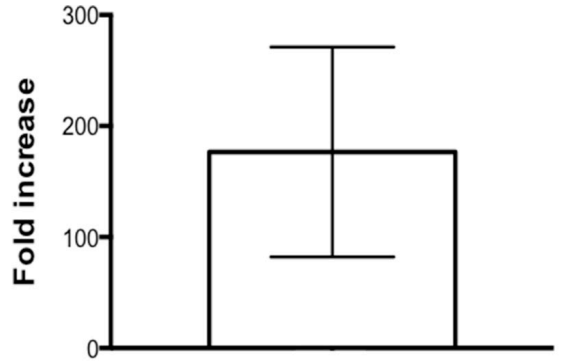

B

a)

$\square \%$ of CD4 $4^{+} \mathrm{CD} 25^{\mathrm{hi}} \mathrm{CD} 127^{-}$
$\square \%$ of CD4 ${ }^{+} \mathrm{FoxP}^{+}$
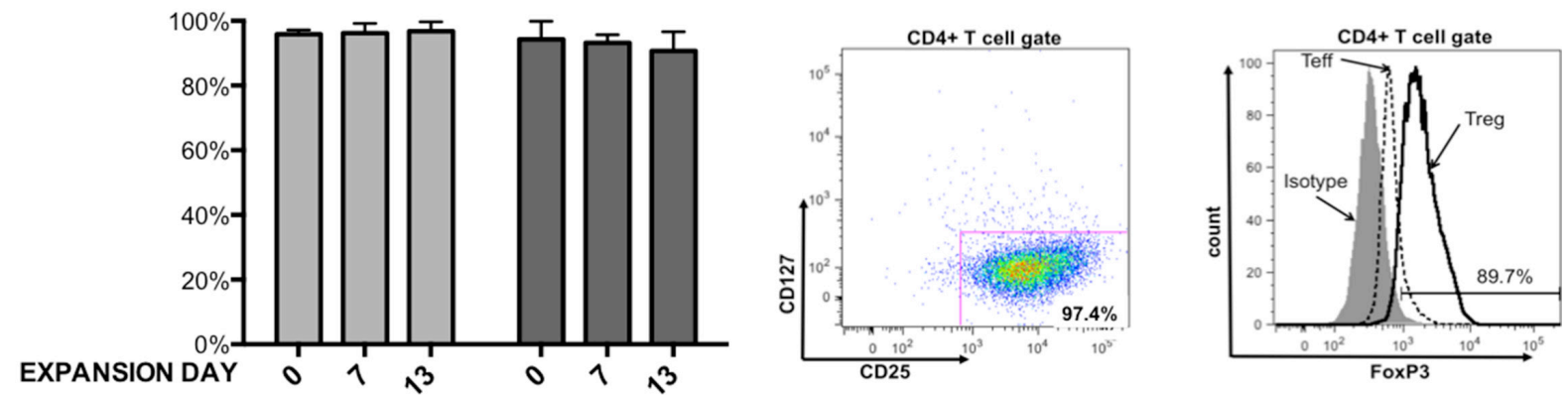

C

a)

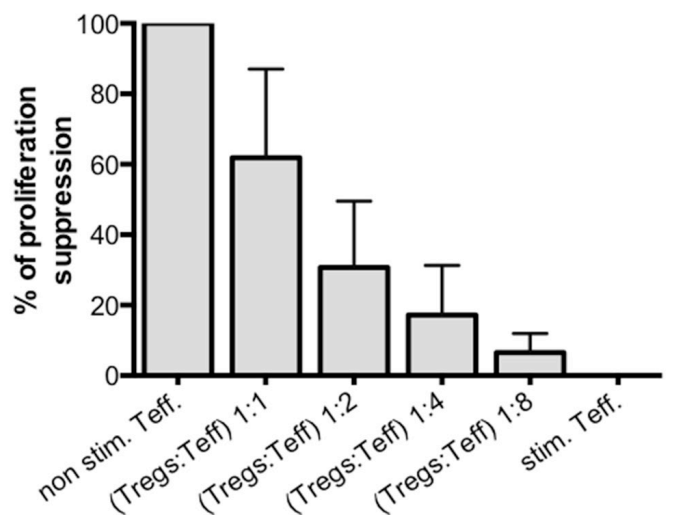

fungal and bacterial growth in the extracted sample. After expansion of isolated Tregs stimulated with antiCD3/anti-CD28-coated beads during 13 day in vitro culture in medium supplemented with IL-2 we obtained $1.77 \times 10^{9}$ Treg cells. During bead removal process on ClinExVivo ${ }^{\mathrm{TM}} \mathrm{MPC}^{\circledR}$ magnet, we observed $10 \%$ loss in Treg cell number, giving $1.6 \times 10^{9}$ cells in the final Treg product.

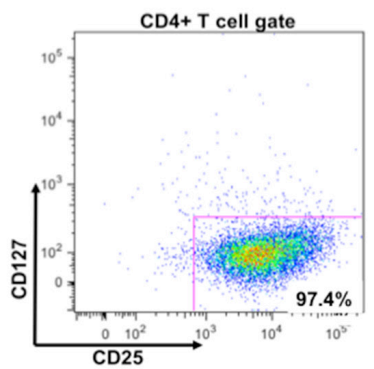

b)

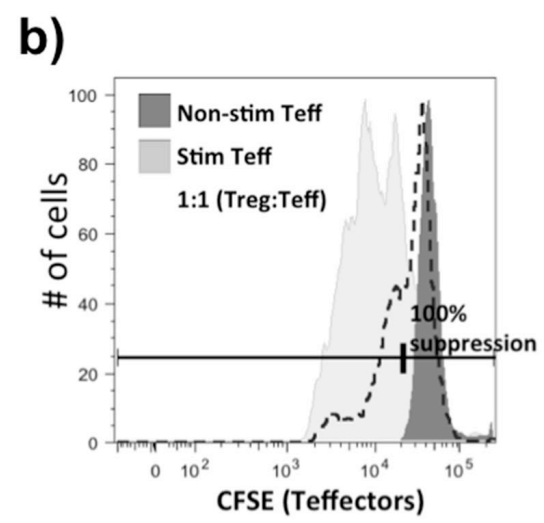

Figure 1: Results from pre-clinical grade Treg expansions. (A) Fold increase in Treg cell number achieved during pre-validation expansions. (B) Treg phenotype during expansion, a) \% of $\mathrm{CD} 4{ }^{+} \mathrm{CD} 25^{\text {hi }} \mathrm{CD} 127^{\mathrm{lo} /}$ (light gray bars) and $\% \mathrm{CD} 4{ }^{+} \mathrm{FoxP} 3^{+}$(dark gray bars) within expanded Tregs was maintained on high level, b) representative flow cytometric dot plot showing frequency of CD $4^{+} \mathrm{CD} 25^{\mathrm{hi}} \mathrm{CD} 127^{\mathrm{lo} /}$ cells in analyzed sample of Tregs, c) representative flow cytometric histogram overlay showing analysis of FoxP3 expression in sample of Tregs (black line), expanded on the same time Teffectors that served as the control (dotted line) and isotype (on gray) based on which gate was placed. (C) Suppressive abilities of expanded Tregs in in vitro assay. (a) Expanded Tregs indicated good suppressive abilities, (b) representative of flow cytometric histogram showing CFSE signal of stained Teffectors; non-stimulated with anti-CD3/CD28 beads Teffectors (dark gray) served as control for $100 \%$ suppression of proliferation and $\%$ of suppression in conditions with Tregs were calculated using following formula: ( $\%$ of suppressed cells in Teff. co-cultured with Tregs $\times 100) / \%$ of suppressed cells in non-stimulated Teff. Results throughout the figure are expressed as mean $\pm \mathrm{SD} ; n \geq 3$. 


\section{Monitoring of Treg phenotype as a quality control of Treg expansion}

For quality control, we checked if the isolation and expansion process had affected the phenotype of Treg cell population. We measured and compared specific markers expression (CD4, CD25, CD127, FoxP3) just after Treg sorting- day 0 , before re-stimulation at day 7 , and at the end of the expansion- on day 13. Isolated Tregs maintained their specific phenotype at a stable level during expansion (> 96\% of cells were $\mathrm{CD} 4{ }^{+} \mathrm{CD} 25^{\mathrm{hi}} \mathrm{CD} 127^{\mathrm{lo} /-}$ at all above listed time points (Figure 2A). Transcription factor FoxP3 was also expressed at high level in isolated/expanded Tregs - \% of $\mathrm{CD}^{+} \mathrm{FoxP}^{+}$Tregs was $77.9 \%$ just after isolation, $89.3 \%$ and $90.6 \%$ at day 7 and 13 , respectively (Figure 2A). Such characteristic of FoxP3 expression was unique for Tregs and distinct from Tefector cells, which were analyzed in parallel for the same marker expression and served as the control (Figure 1B(c)).

It was suggested that naïve Tregs expressing CD45RA and CD62L markers are better candidates for expansion due to their stability and increased suppressive abilities in comparison to memory Treg subsets $[24,25,31-33]$. Therefore, we also analyzed frequency of

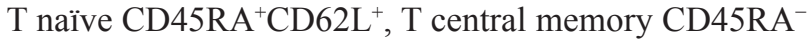
$\mathrm{CD}^{2} \mathrm{~L}^{+}$and $\mathrm{T}$ effector memory CD45RA ${ }^{-} \mathrm{CD} 62 \mathrm{~L}^{-}$subsets within sorted and expanded Tregs.

Before expansion, $44.5 \%$ Tregs expressed $\mathrm{CD}_{5} \mathrm{RA}^{+} \mathrm{CD} 62 \mathrm{~L}^{+}$and $50.1 \% \mathrm{CD}^{2} 5 \mathrm{RACD}^{-} \mathrm{CD}^{+} \mathrm{L}^{+}$(Figure 1B). Over the time of expansion, CD45RA expression on Tregs decreased and proportion of naive and central memory subsets changed to $26.5 \%$ and $68.6 \%$, respectively (Figure 2B). However, the frequency of T effector memory CD45RA CD62 $\mathrm{L}^{-}$subset that is considered to contain "non-suppressive" Tregs [33] was low before and after the expansion (Figure 2B).

\section{Expanded Tregs have ability to suppress $\mathbf{T}$ cell proliferation in vitro}

Functionality and potency of expanded Tregs was tested in in vitro suppression of proliferation assay. This assay was performed at the end of expansion and served for information only. As shown in Figure 3, expanded Tregs in the final product provided the ability to suppress proliferation of Teffector cells in a dose-dependent manner.

\section{Ex vivo expanded Tregs prepared as a final Treg product fulfilled all release criteria}

As required by FDA, biological product should be characterized with appropriate tests for the identity, purity, safety and potency. Those measures and acceptance values for the release criteria of the product should be established prior to clinical application [29]. Additionally, all these tests need to be validated to assure accuracy, precision, specificity, suitability and robustness with identification of criteria for the test acceptance, mean numerical limits, ranges or other attributes/ variables [29].

Table 1 presents all release criteria that we established for the final Treg product in our protocol. Values for acceptance and results from the validation expansion are depicted as well. All tests used for release criteria assessment were selected accordingly to the FDA recommendation and performed by College of American Pathologists (CAP)- certified laboratories that routinely performed validations of assays they utilize. Our final Treg product manufactured according to our established protocol fulfilled all the release criteria. Details and numerical values are shown in Table 1.
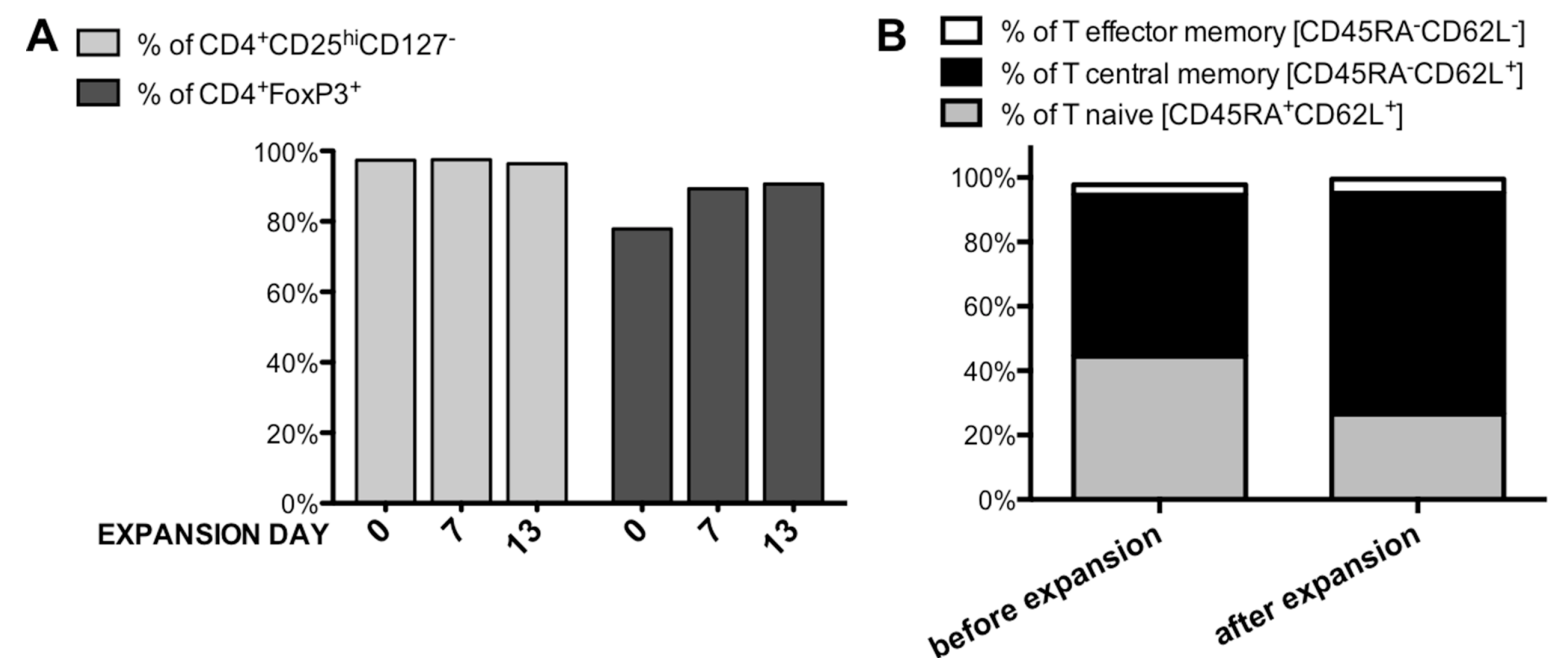

Figure 2: Treg Phenotype during clinical-grade Treg isolation and expansion process. (A) Isolated and expanded Tregs presented stable $\mathrm{CD} 4{ }^{+} \mathrm{CD} 25^{\text {hi }} \mathrm{CD} 127^{10 /}$ phenotype (light gray bars) together with maintained high expression of transcription factor FoxP3 (dark gray bars) during all Quality Check Points, (B) The percentage of naïve, central memory and effector memory cells in Tregs before and after 13-day expansion; $n=1$. 


\begin{tabular}{|c|c|c|c|}
\hline $\begin{array}{l}\text { RELEASE } \\
\text { CRITERIA }\end{array}$ & $\begin{array}{c}\text { MINIMUM } \\
\text { RELEASE CRITERIA } \\
\text { (SPECIFICATION) }\end{array}$ & METHOD & RESULT FROM VALIDATION \\
\hline Sterility & $\begin{array}{l}\text { "no aerobic, anaeorbic and } \\
\text { fungal growth" }\end{array}$ & $\begin{array}{l}\text { CAP-certified Clinical } \\
\text { Microbiology Laboratory }\end{array}$ & $\begin{array}{l}\text { "no aerobic, anaeorbic and } \\
\text { fungal growth" }\end{array}$ \\
\hline Endotoxin & $<5 \mathrm{EU} / \mathrm{kg}$ & $\begin{array}{l}\text { EndoSafe PTS Endotoxin } \\
\text { System; calculated for an } \\
\text { average } 70 \mathrm{~kg} \text { person receiving } \\
\text { final product }\end{array}$ & $1.28 \mathrm{EU} / \mathrm{kg}$ \\
\hline Mycoplasma & $<0.8$ & $\begin{array}{l}\text { Lonza MycoAlert Mycoplasma } \\
\text { Assay }\end{array}$ & 0.399 \\
\hline $\begin{array}{l}\text { Determination of } \\
\text { Residual Beads }\end{array}$ & $\begin{array}{l}<100 \text { beads } \\
\text { per } 3 \times 10^{6} \text { cells }\end{array}$ & $\begin{array}{l}\text { counted on hemocytometer } \\
\text { after cell permeabilization }\end{array}$ & 91 beads per $3 \times 10^{6}$ cells \\
\hline$\%$ of CD4+ cells & $>90 \%$ & $\begin{array}{l}\text { flow cytometry in CAP- } \\
\text { certified Clinical Hematology } \\
\text { Laboratory }\end{array}$ & $99.14 \%$ \\
\hline$\%$ of FoxP3+ cells & $>60 \%$ & $\begin{array}{l}\text { flow cytometry in CAP- } \\
\text { certified Clinical Hematology } \\
\text { Laboratory }\end{array}$ & $90.64 \%$ \\
\hline$\%$ of CD8+ cells & $<5 \%$ & $\begin{array}{l}\text { flow cytometry in CAP- } \\
\text { certified Clinical Hematology } \\
\text { Laboratory }\end{array}$ & $0.35 \%$ \\
\hline Viability & $>75 \%$ & $\begin{array}{l}\text { flow cytometry in CAP- } \\
\text { certified Clinical Hematology } \\
\text { Laboratory }\end{array}$ & $97.79 \%$ \\
\hline
\end{tabular}

\section{DISCUSSION}

Tregs for clinical application need to be manufactured according to a protocol that follows cGMP guidelines and FDA requirements. Additionally, each step of the procedure needs to be optimized for the successful final outcome- allowing to obtain high quality and sufficient quantity, well defined, viable, functional and sterile biological cell product. In our clinical-grade Treg manufacturing protocol we perform leukapheresis instead of drawing a unit of blood $[6,10,11]$ or utilizing banked blood from umbilical cord (UCB) $[8,9]$. Such approach allows for starting with much higher initial number of cells for processing compared to other mentioned initial products. One unit of whole blood or UCB can yield in average 4-7.5 $\times 10^{6}$ Tregs whereas over 10-20 times more Tregs- $\left(10^{8}\right)$ can be found in the product of leukapheresis [34-36]. The other advantage is, that during leukapheresis only white blood cells are collected and erythrocytes are returned to donor's circulation instead of being wasted. It is a feasible procedure, routinely performed in hospital blood bank units. During our validation processing, (even though we utilized only a small fraction $(1 / 6-1 / 8)$ of product of leukapheresis), we still obtained $9.7 \times 10^{6}$ Tregs after sorting, which is sufficient for further clinical processing. Even if the fold increase in cell number is lower than 100 during the ex-vivo expansion, the number of isolated cells allows the process to achieve around 1 billion Tregs, which would be sufficient for clinical application with our target dose of $10 \times 10^{6}$ Tregs per kg of body weight of the patient. Such Treg number is currently considered sufficient for testing in patients with autoimmune conditions as well as in transplantation for immuno tolerogenic effect and longterm graft survival [37].

In the next step, we introduced CD4 positive selection to obtain pre-enriched cells. In contrast to direct Treg sorting from leukocytes, our approach demands lower number of cells submitted to sorting. Our protocol is less time-consuming and requires lower number and amount of costly clinical grade antibodies (CD4, CD25, CD127) for sorting. In our approach, only one vial of clinical-grade CliniMACS ${ }^{\circledR}$ CD4 reagent is used for $\mathrm{CD}^{+}$cells preenrichment step and one for subsequent sorting. Of note, since CD4 antibodies used for CliniMACS ${ }^{\circledR}$ separation 
and for sorting are based on different clones, performing both procedures one after another is still efficient.

In our protocol, we decided to use FACS instead of immunomagnetic separation in order to obtain highly pure Treg population defined as $\mathrm{CD} 4^{+} \mathrm{CD} 25^{\text {high }} \mathrm{CD} 127^{-/ \mathrm{lo}}$ cells. In contrast, immunomagnetic method includes during the selection process also T cells with intermediate or even low level of CD25 expression, which leads to contamination of the isolation product with also non-Treg cells. Therefore, protocols based only on immunomagnetic selection must use rapamycin during in vitro expansion to suppress proliferation of contaminating cells, which otherwise can overgrow the Treg population [34, 38, 39]. Rapamycin present in the culture media during expansion also suppresses Treg proliferation [26, 40], so more intensive stimulation with anti-CD3/CD28 beads is necessary, which can lead to cell exhaustion and expansion failure. Only FACS allows isolating cells expressing selectively high level of CD25 and obtaining highly purified Tregs without need for rapamycin. The disadvantage of FACS is that, so far there are no cGMPcompliant cell sorters widely available. Therefore, in order to meet cGMP requirements for clinical cell processing, we placed the BD FACSAriaIII sorter into the custommade biosafety cabinet inside cGMP facility. We also performed built-in "preparation for aseptic sort procedure" to clean interior surfaces of the sorter, [41]. We also used gas-sterilized nozzle with sample line - the parts that are in contact with cells during sorting in order to eliminate the risk of contamination. Moreover for a quality control, before running cells for sorting, we sent a sample of sheath fluid for sterility testing to prove that the sorter is free of microbiological contaminants. FDA has already approved similar protocols for cleaning and maintenance under IND for example in Dr Tang/Bluestone's lab in UCSF (personal communication).

In our protocol, Tregs are submitted for ex vivo expansion for 13 days with two rounds of bead stimulation. In previous set of experiments, we set optimal time frame for Treg expansion as 13 days $[6,11,26]$. It allows generation of sufficient number of Tregs with well preserved phenotype stability and function [26].

We expanded Tregs after stimulation with anti-CD3/ CD28 beads and in the presence of IL-2 in concentration of $1,000 \mathrm{UI} / \mathrm{ml}$ in a culture medium. We chose such concentration of IL-2 based on previously published protocols [11, 23, 26, 30, 42]. Moreover, it has been shown that higher concentration of IL-2 in the culture makes Tregs less prone to apoptosis caused by activationinduced cell death (AICD) [43]. During expansion both stimulatory pathways: via TCR/CD28 co-stimulation and IL-2 are shown to support the function and viability of Tregs [43]. Additionally, in our previous research-grade Treg expansions we also tested different concentrations of IL-2 (100; 1000; 10,000 UI/ml) and we found that concentration $1000 \mathrm{UI} / \mathrm{ml}$ provides the highest fold increase in Treg cell number with preservation of Treg viability and phenotype (unpublished data).

Tregs processed according to our protocol maintained their phenotype and function, which was confirmed at different time points of expansion and in in vitro suppression of proliferation assay. At the end of Treg processing anti-CD3/CD28 beads used for stimulation were removed from Treg cell product utilizing a clinicalgrade magnet according to the previously published assay, which we validated in our laboratory $[8,44]$.

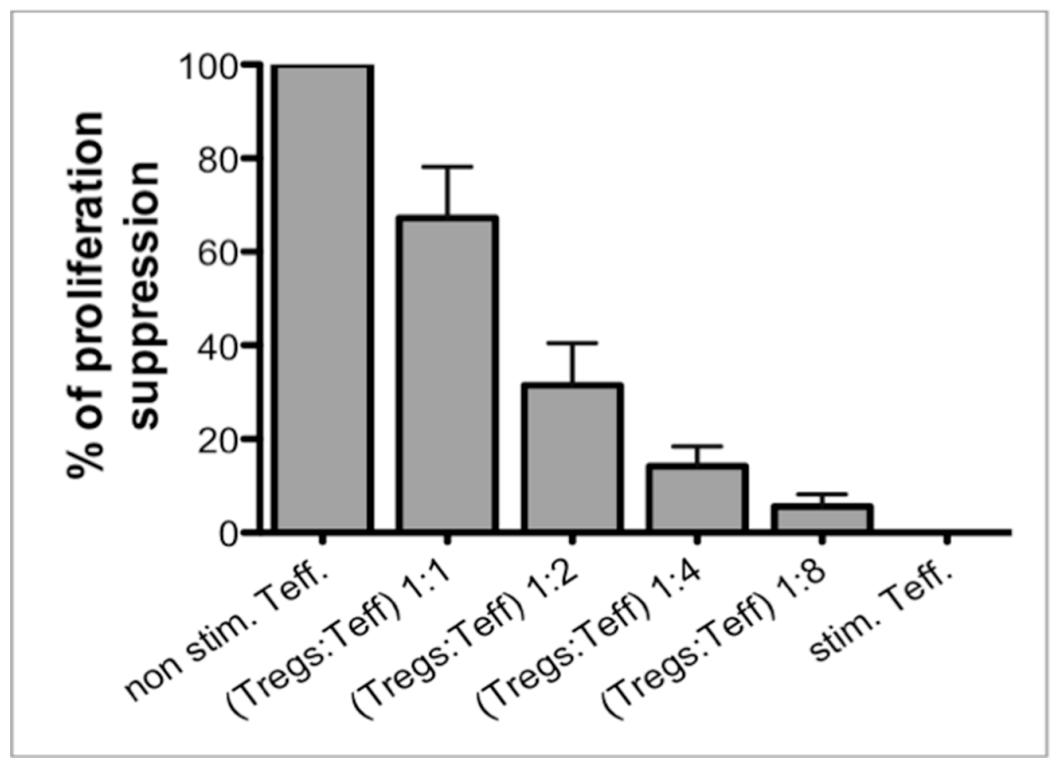

Figure 3: Suppression of proliferation assay as a post-expansion Treg functionality test. (A) Expanded Tregs in the Final Product were able to suppress proliferation of CFSE-stained Teffectors (Teff) in a dose-dependent manner. Results are expressed as mean $\pm \mathrm{SD} ; n=3$. 
To characterize our final Treg product, we established appropriate release criteria according to the FDA requirements [29, 45] and previously approved Treg clinical trials in the USA [8-10]. It is essential that all quality and quantity checks for final product release criteria are performed in clinical, CAP- certified laboratories or utilizing properly validated own assays. For convenience, we sent out samples for sterility, $\%$ of $\mathrm{CD}^{+}, \%$ of $\mathrm{FoxP}^{+}, \%$ of $\mathrm{CD}^{+}$determination to the clinical hospital laboratories. We developed and validated own testing methods, only when otherwise unavailable. Our final Treg product met all the release criteria. We are aware of the shortcomings of these criteria; however, this is probably the best currently available panel, which can be analysed during the process of real-time product release. Whenever methodology allows to obtain the results within the timeframe of release, novel markers can be also included. For example, the analysis of the FOXP3-TSDR does not allow to include this trait as a part of the release criteria due to time-consuming processing of such analysis.

In summary, we described our Treg ex vivo expansion protocol successfully introducing leukapheresis as an alternative to blood drawing or UCB as the source of leukocytes. It provides higher initial number of Tregs and limits the risk of failure during the expansion phase. Having an excessive final number of Tregs not only allows the investigator to apply them instantly after expansion into patients, but also to cryopreserve a remaining dose of cells for later clinical use. This has a major practical advantage of opportunity for subsequent, repetitive dose as well as optimal timing of application. Additional introduction of CD4 positive selection limits number of cells and cost of sorting. In this study, we validated our Treg isolation and expansion protocol providing clinical-grade Treg product. After IND approval it can be further tested for safety and effectiveness in clinical trials as potential immunotherapy in cell/organ transplantation and immune disorders.

\section{MATERIALS AND METHODS}

\section{Clinical-grade regulatory $\mathbf{T}$ cell isolation}

Tregs were isolated in a two-step process. In the first step, $\mathrm{CD}^{+}$cells were selected from leukapheresis product (AllCells, Alameda, CA, USA) obtained from healthy volunteers. In that process, immunomagnetic isolation on CliniMACS ${ }^{\circledR}$ device (Miltenyi Biotec $\mathrm{GmbH}$, Bergisch Gladbach, Germany) with clinical-grade reagents were utilized. The $\mathrm{CD}^{+}$cells isolation was performed without delay after receipt of leukapheresis product as suggested by the provider. CD4 isolation was performed on Miltenyi Biotec CliniMACS Instrument (V2.40) following user manual for cell preparation and magnetic labeling: after adding CliniMACS ${ }^{\circledR}$ CD4 Reagent, the cell preparation bag was placed flat on an orbital rotator at room temperature for 30 minutes. After magnetic separation process, $\mathrm{CD}^{+}$cells were centrifuged, suspended in X-VIVO ${ }^{\mathrm{TM}} 20$ medium (Lonza Walkersville, Inc., Walkersville, MD, USA) supplemented with 10\% human AB serum (Valley Biomedical Products \& Services, Inc., Winchester, VA, USA) and split into portions each containing $100 \times 10^{6}$ cells. One of the portions was prepared directly for staining in $5 \mathrm{ml}$ conical tube (BDBioscience, Bedford, MA, USA) and the rest of them put in the T-75 flasks (BDBiosciences, Bedford, MA, USA) and placed for short-term culture in a $37^{\circ} \mathrm{C}$, $95 \%$ humidity, $5 \% \mathrm{CO}_{2}$ incubator until the sorting of the first and subsequent portions was completed. Totally $5 \times 10^{8} \mathrm{CD}^{+}$cells were stained with clinical-grade fluorochrome-conjugated monoclonal antibodies: CD4 PerCP, CD25 APC, CD127 PE (BDBiosciences, San Jose, CA, USA). Next Tregs (CD4 $4^{+} \mathrm{CD} 25^{\text {hi }} \mathrm{CD} 127^{-}$cells) were sorted accordingly to the gating strategy shown on the Figure 4 with FACSAria III cell sorter (BDBiosciences, San Jose, CA, USA) adapted in a custom-designed biosafety cabinet (NuAire, Plymouth, MN, USA) inside our cGMP clean room facility class 10,000 utilizing gassterilized $70 \mu \mathrm{m}$ nozzle and sample line. Sorting was performed with setting of "precision mode" and speed $<10,000$ events/sec to sort highly pure Treg population. During the 48-hour sorting process, samples with collected Tregs were centrifuged, re-suspended in vivo ${ }^{\mathrm{TM}}$ 20 medium (Lonza Walkersville, Inc., Walkersville, MD, USA) supplemented with 10\% human AB serum (Valley Biomedical Products \& Services, Inc., Winchester, VA, USA) and $1000 \mathrm{U} / \mathrm{ml}$ of interleukin-2 (Proleukin ${ }^{\circledR}$, Novartis Pharmaceuticals Canada Inc., Dorval, Quebec, Canada) - Treg Culture Medium and placed for a shortterm culture in a $37^{\circ} \mathrm{C}, 95 \%$ humidity, $5 \% \mathrm{CO}_{2}$ incubator. All collected samples during sorting were checked for the purity - $\%$ of $\mathrm{CD} 4{ }^{+} \mathrm{CD} 25^{\mathrm{hi}} \mathrm{CD} 127^{\mathrm{lo} /}$ cells. During sorting, a portion of $\mathrm{T}$ effectors $\left(\mathrm{CD} 4{ }^{+} \mathrm{CD} 25^{\mathrm{lo}} \mathrm{CD} 127^{+}\right.$cells) was also separated (Figure 4) at the same time for further Treg control assays.

\section{Clinical-grade Treg expansion}

After sorting, Treg samples with the purity $\geq$ $95 \%$ ( $\%$ of $\mathrm{CD}^{+} \mathrm{CD} 25^{\mathrm{hi}} \mathrm{CD} 127^{\mathrm{lo} /-}$ cells) were pooled together, counted and placed in 96-well U-bottom tissue culture plates (BD Biosciences, Durham, NC, USA) at a concentration of $2 \times 10^{5}$ cells per well suspended in Treg Culture Medium. For Treg stimulation MACS ${ }^{\circledR}$ GMP ExpAct Treg Beads (Miltenyi Biotec GmbH, Bergisch Gladbach, Germany) at cell: bead ratio 1:1 were used. Tregs were cultured in a $37^{\circ} \mathrm{C}, 95 \%$ humidity, $5 \% \mathrm{CO}_{2}$ incubator and were split with addition of fresh Treg Culture Medium every 24 - 48 hours to maintain the concentration of $\sim 2 \times 10^{5}$ cells per well. At day 7 , Tregs were collected, counted and re-stimulated with fresh beads at the same ratio as for initiation of expansion. 
On the 13th day, Tregs were collected, counted and suspended in the Final Treg Product Medium that contained $49.02 \%$ of Plasmalyte A (Baxter Healthcare Corporation, Deerfield, IL, USA), $49.02 \%$ of Dextrose, $5 \%$ and $0.45 \%$ $\mathrm{NaCl}$ (Baxter Healthcare Corporation, Deerfield, IL, USA), $1.96 \%$ of $25 \%$ Human Serum Albumin (Baxter Healthcare Corporation, Deerfield, IL, USA). Just after collection, MACS $^{\circledR}$ GMP ExpAct Treg Beads were removed on ClinExVivo $^{\mathrm{TM}}$ MPC $^{\circledR}$ magnet (Life Technologies, Dynal Biotech ASA, Norway) in bags (Charter Medical, Ltd., Winston-Salem, NC, USA) connected together to create a closed system. After bead removal, $5 \mathrm{ml}$ sample from Treg suspension was taken for a final Treg product count and testing. All procedures of Treg isolation and expansion were performed in cGMP clean room facility class 10,000. Samples for sterility testing were sent at subsequent steps of the procedure: from leukapheresis product, after $\mathrm{CD}^{+}$ cells isolation, Treg sorting and after bead removal from Tregs. The schema of protocol for Treg isolation and expansion as timeline is shown in Figure 5.

\section{Quality control checks of Treg expansion}

Just after Treg sorting- day 0 , as well as at day 7 and 13, quality of Tregs were checked by FoxP3, CD4, CD25, CD127, CD45RA and CD62L expression analysis. Briefly, $2 \times 10^{5}$ Tregs were harvested and processed according to manufacturer instructions of the FoxP3/Transcription Factor Staining Buffer Set (eBioscience, Inc., San Diego, CA, USA) and stained with the following antibodies: FoxP3 FITC (eBioscience, Inc., San Diego, CA, USA), CD4 PerCP, CD25 APC, CD127 PE, CD45RA PE-Cy7 (BDBiosciences, San Jose, CA, USA), CD62L APCAlexa Fluor ${ }^{\circledR} 750$ (Invitrogen, Frederick, MD, USA). Samples were acquired on LSRFortessa ${ }^{\mathrm{TM}}$ Cell Analyser (BDBiosciences, San Jose, Cam, USA) and analyzed on Flow Jo $^{\circledR}$ software (FlowJo, LLC., Ashland, OR, USA). Isotype and Fluorescence Minus One (FMO) controls were used for gate settings.

\section{Suppression of proliferation assay}

To analyze Treg function after the expansion, we performed suppression of proliferation assay. Teffectors were stained with $5 \mu \mathrm{M}$ carboxyfluorescein diacetate succinimidyl ester (CFSE) (Molecular Probes, Inc., Invitrogen, Eugene, OR, USA) and plated in concentration of $5 \times 10^{4}$ cells per well on 96 well u-bottom plates in cocultures with expanded Treg cells in different proportions (Treg:Teffector - 1:1, 1:2, 1:8). Cells were cultured in the presence of anti-CD3, anti-CD28-coated magnetic beads (LifeTechnologies, USA) at 1:1 bead to cell ratio and IL-2 at concentration $100 \mathrm{U} / \mathrm{ml}$. Assay was prepared in triplicate. After 4 days of co-culture, CFSE dye dilution

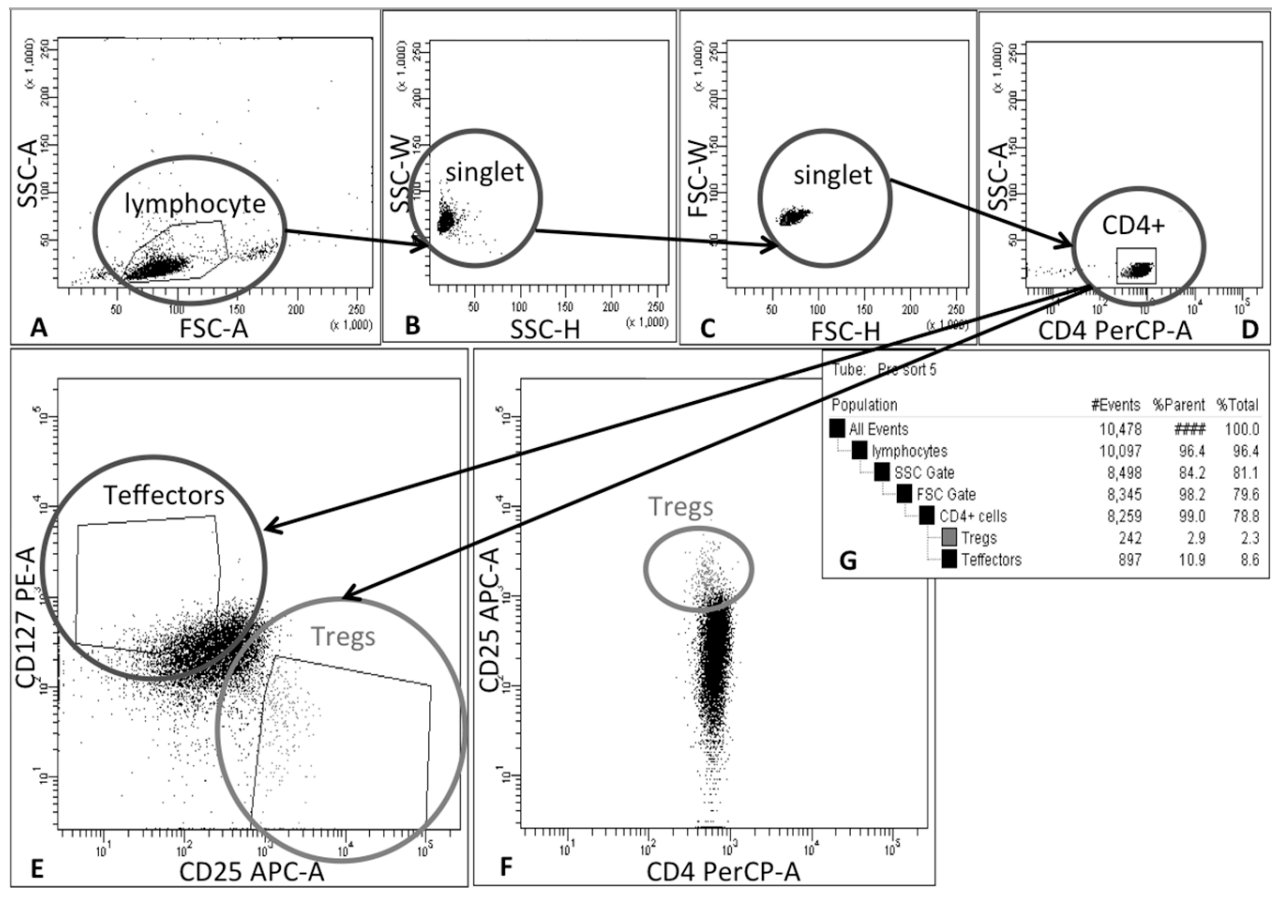

Figure 4: Schema of gating strategy for Treg sorting. Tregs were isolated in 2-step process: firstly, CD4 ${ }^{+}$cells were pre-enriched from leukapheresis product via immunomagnetic positive selection on CliniMACS ${ }^{\circledR}$ device and then cells were stained with monoclonal antibodies and separated by Fluorescence Activated Cell Sorting (FACS). During FACS cells were gated as follows: (A) lymphocytes were identified on forward (FSC) and side-scatter (SSC) plot, (B) and (C) doublets were excluded by applying SSC-H vs SSC-W and FSC-H vs FSC-W gates, (D) followed by CD4 ${ }^{+}$cell gating. (E) Finally, Tregs and Teffectors were gated as CD25 $5^{\text {hi }} \mathrm{CD} 127^{\mathrm{lo} /-}$ and $\mathrm{CD} 25^{\mathrm{lo} /-} \mathrm{CD} 127^{+}$ cells, respectively; (F) dot-plot CD4 PerCP vs CD25 APC was used as a reference for correct Treg gating based on lower CD4 expression in Treg population than in Teffectors. $(\mathbf{G})$ table with population hierarchy and statistics generated by FACSDiva Software during cell sorting on FACSAria III cell sorter (BD Biosciences, San Jose, CA, USA 
was measured using LSRFortessa ${ }^{\mathrm{TM}}$ Cell Analyser. Percentage of suppression was calculated in relation to $100 \%$ in condition of non-stimulated Teffectors.

\section{Release criteria of the final Treg product}

The following Release Criteria were established based on FDA requirements and previously described clinical trials with Tregs conducted in USA: 1) sterility - to exclude presence of aerobic or anaerobic bacterial and fungal growth; 2) mycoplasma test (MycoAlert Mycoplasma Assay, Lonza Walkersville Inc., Walkersville, MD, USA) $<0.8 ; 3$ ) endotoxin $\left(\right.$ EndoSafe ${ }^{\circledR}$ PTS $^{\text {TM }}$ Endotoxin System, Charles River, Charleston, SC, USA) - < 5 EU/kg; 4) determination of residual expansion beads $-<100$ per $3 \times$ $10^{6}$ cell, 5) viability with 7 AminoActinomycin D (7AAD) - > 75\%; 6) $\%$ of FoxP3 ${ }^{+}$cells - > 60\%, 7) $\%$ of CD4 ${ }^{+}$ cells $->90 \%, 8) \%$ of $\mathrm{CD}^{+}$cells $-<5 \%$. Viability with $7 \mathrm{AAD}, \%$ of FoxP $3^{+}, \mathrm{CD}^{+}$and $\mathrm{CD}^{+}$cells were determined by flow cytometry. Most of the assays for release criteria were validated and performed by College of American Pathologists (CAP)- certified laboratories. Determination of residual expansion beads was performed "in house" after assay validation. Five $\mathrm{ml}$ of Treg suspension was retrieved from the infusion bag after beads removal and Tregs were tested to fulfill established Release Criteria.

\section{Pre-clinical grade Treg isolations and expansions}

A non-clinical grade Treg isolations and expansions $(N=3)$ were performed in the same manner as described for clinical-grade procedures, but with use of non-clinical grade antibodies for Treg sorting: CD4PerCP-Cy ${ }^{\mathrm{TM}} 5.5$, CD25APC, CD127 PE (BD Biosciences, San Jose, CA, USA). More than $1 \times 10^{6}$ were sorted and they were expanded for 13 days as described above with monitoring of Treg stability by checking Treg markers (CD4, CD25, CD127, FoxP3) expression. Treg functionality was checked in suppression of proliferation assay at the end of expansion. After expansion, Tregs were collected and counted to assess fold increase in cell number.

\section{Ethical considerations}

We obtained de-identified human cell leukapheresis product for the all experiments from the commercial vendor AllCells, Alameda, CA, USA, therefore the study was exempt from the Institute Review Board (IRB) review. In addition, vendor certified that the product was obtained from volunteers participating in an IRB or Human Subject Committee approved donor program and had current IRB approval. Vendor also certified that all donors provided informed consent for use of the cell for any research study.

\section{ACKNOWLEDGMENTS}

We would like to wholeheartedly thank Dr. Qizhi Tang from the University of California San Francisco and Dr. Marisa Alegre from The University of Chicago for guidance and all her valuable suggestions regarding Treg processing for clinical application.

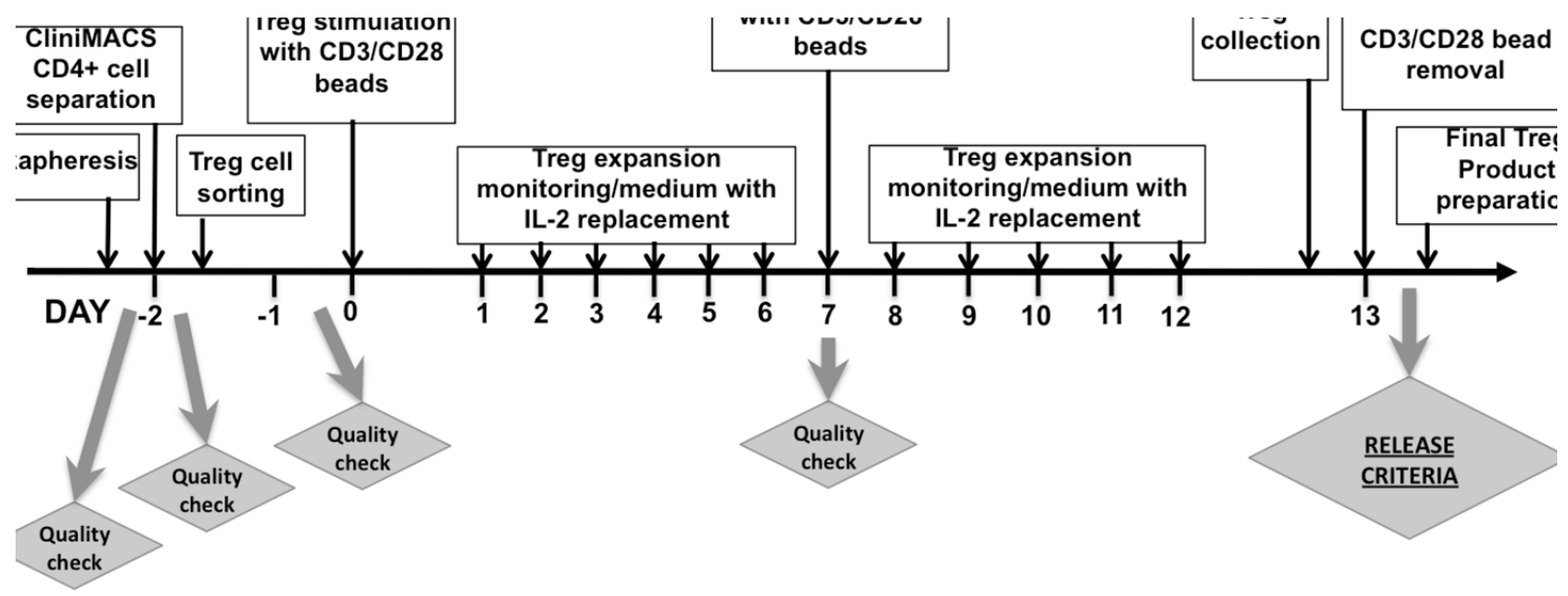

Figure 5: Timeline of Treg isolation and ex-vivo expansion. The flowchart shows the procedure from the receipt of leukapheresis product, through $\mathrm{CD}^{+}$cells separation on CliniMACS ${ }^{\circledR}$ device, Treg sorting (details of sorting strategy is described in Figure 4), Treg expansion, collection and preparation of Final Treg Product with indication of Quality Check Points during the process. During 48-hour sorting process, samples with sorted Tregs were centrifuged and collected, Tregs were re-suspended in Treg Culture Medium with IL-2 for short-term culture. After sorting, Tregs were pooled together, counted and distributed into 96-well U-bottom plates at concentration $2 \times 10^{5}$ cells per well. Next, anti-CD3/CD28-coated beads were added and Tregs were expanded for 13 days. Treg culture was maintained on daily basis and Tregs were split with addition of fresh medium with IL-2. On day 7, Tregs from all wells were collected, sample of Tregs was retrieved for phenotype and viability analysis as Quality Check of expansion process. Then, Tregs were counted, re-distributed on plates and re-stimulated with fresh anti-CD3/CD28-coated beads. At day 13 of expansion, Tregs were collected, suspended in Final Treg Product Medium and anti-CD3/CD28 beads were removed on ClinExVivo ${ }^{\mathrm{TM}}$ MPC $^{\circledR}$ magnet. After bead removal, sample of Treg cell suspension was taken for Final Treg Product Testing. 


\section{CONFLICTS OF INTEREST}

The authors do not have any conflicts of interest to declare.

\section{FUNDING}

This project was supported by CRC- National Center for Advancing Transitional Sciences of the NIH Grant \# UL1TR000430 and National Centre for Research and Development, Poland: grant \# STRATEGMED1/233368/1/ NCBR/2014.

\section{REFERENCES}

1. Corthay A. How do Regulatory T Cells Work? Scand. J Immunol. 2009; 70:326-36.

2. Josefowicz SZ, Lu L-F, Rudensky AY. Regulatory T Cells: Mechanisms of Differentiation and Function. Annu Rev Immunol. 2012; 30:531-64.

3. Shevach EM. Regulatory T cells in autoimmmunity*. Annu Rev Immunol. 2000; 18:423-49.

4. Shevach EM. Biological functions of regulatory T cells. Adv Immunol. 2011; 112:137-76.

5. Hall BM. T Cells: Soldiers and Spies-The Surveillance and Control of Effector T Cells by Regulatory T Cells. Clin J Am Soc. Nephrol. CJASN 2015.

6. Trzonkowski P, Bieniaszewska M, Juścińska J, Dobyszuk A, Krzystyniak A, Marek N, Myśliwska J, Hellmann A. First-in-man clinical results of the treatment of patients with graft versus host disease with human ex vivo expanded CD4+CD25+CD127- T regulatory cells. Clin Immunol Orlando Fla. 2009; 133:22-6.

7. Di Ianni M, Falzetti F, Carotti A, Terenzi A, Castellino F, Bonifacio E, Del Papa B, Zei T, Ostini RI, Cecchini D, Aloisi T, Perruccio K, Ruggeri L, et al. Tregs prevent GVHD and promote immune reconstitution in HLA-haploidentical transplantation. Blood. 2011; 117:3921-8.

8. Brunstein CG, Miller JS, Cao Q, McKenna DH, Hippen KL, Curtsinger J, Defor T, Levine BL, June CH, Rubinstein P, McGlave PB, Blazar BR, Wagner JE. Infusion of ex vivo expanded $\mathrm{T}$ regulatory cells in adults transplanted with umbilical cord blood: safety profile and detection kinetics. Blood. 2011; 117:1061-70.

9. Brunstein CG, Miller JS, McKenna DH, Hippen KL, DeFor TE, Sumstad D, Curtsinger J, Verneris MR, MacMillan ML, Levine BL, Riley JL, June CH, Le C, et al. Umbilical cord blood-derived $\mathrm{T}$ regulatory cells to prevent GVHD: kinetics, toxicity profile, and clinical effect. Blood. 2016; 127:1044-51.

10. Bluestone JA, Buckner JH, Fitch M, Gitelman SE, Gupta S, Hellerstein MK, Herold KC, Lares A, Lee MR, Li K, Liu W, Long SA, Masiello LM, et al. Type 1 diabetes immunotherapy using polyclonal regulatory $\mathrm{T}$ cells. Sci Transl Med. 2015; 7:315ra189.
11. Marek-Trzonkowska N, Mysliwiec M, Dobyszuk A, Grabowska M, Techmanska I, Juscinska J, Wujtewicz MA, Witkowski P, Mlynarski W, Balcerska A, Mysliwska J, Trzonkowski P. Administration of CD4+CD25highCD127Regulatory T Cells Preserves $\beta$-Cell Function in Type 1 Diabetes in Children. Diabetes Care. 2012; 35:1817-20.

12. Marek-Trzonkowska N, Myśliwiec M, Dobyszuk A, Grabowska M, Derkowska I, Juścińska J, Owczuk R, Szadkowska A, Witkowski P, Młynarski W, JaroszChobot P, Bossowski A, Siebert J, et al. Therapy of type 1 diabetes with CD4+CD25highCD127-regulatory T cells prolongs survival of pancreatic islets - Results of one year follow-up. Clin Immunol. 2014; 153:23-30.

13. Trzonkowski P, Bacchetta R, Battaglia M, Berglund D, Bohnenkamp HR, Brinke A ten, Bushell A, Cools N, Geissler EK, Gregori S, Ham SM van, Hilkens C, Hutchinson JA, et al. Hurdles in therapy with regulatory T cells. Sci Transl Med. 2015; 7:304ps18-304ps18.

14. Safinia N, Vaikunthanathan T, Fraser H, Thirkell S, Lowe K, Blackmore L, Whitehouse G, Martinez-Llordella M, Jassem W, Sanchez-Fueyo A, Lechler RI, Lombardi G. Successful expansion of functional and stable regulatory $\mathrm{T}$ cells for immunotherapy in liver transplantation. Oncotarget. 2016; 7:7563-77. doi: 10.18632/oncotarget.6927.

15. Abbas AK, Benoist C, Bluestone JA, Campbell DJ, Ghosh S, Hori S, Jiang S, Kuchroo VK, Mathis D, Roncarolo MG, Rudensky A, Sakaguchi S, Shevach EM, et al. Regulatory T cells: recommendations to simplify the nomenclature. Nat Immunol. 2013; 14:307-8.

16. Lin X, Chen M, Liu Y, Guo Z, He X, Brand D, Zheng SG. Advances in distinguishing natural from induced Foxp3(+) regulatory T cells. Int J Clin Exp Pathol. 2013; 6:116-23.

17. Piccirillo CA, Thornton AM. Cornerstone of peripheral tolerance: naturally occurring $\mathrm{CD} 4+\mathrm{CD} 25+$ regulatory $\mathrm{T}$ cells. Trends Immunol. 2004; 25:374-80.

18. Karim M, Kingsley CI, Bushell AR, Sawitzki BS, Wood KJ. Alloantigen-induced CD25+CD4+ regulatory T cells can develop in vivo from CD25-CD4+ precursors in a thymusindependent process. J Immunol Baltim. Md 1950 2004; 172:923-8.

19. Miyao T, Floess S, Setoguchi R, Luche H, Fehling HJ, Waldmann H, Huehn J, Hori S. Plasticity of Foxp3(+) T cells reflects promiscuous Foxp3 expression in conventional $\mathrm{T}$ cells but not reprogramming of regulatory $\mathrm{T}$ cells. Immunity. 2012; 36:262-75.

20. Rossetti M, Spreafico R, Saidin S, Chua C, Moshref M, Leong JY, Tan YK, Thumboo J, van Loosdregt J, Albani S. Ex vivo-expanded but not in vitro-induced human regulatory $\mathrm{T}$ cells are candidates for cell therapy in autoimmune diseases thanks to stable demethylation of the FOXP3 regulatory $\mathrm{T}$ cell-specific demethylated region. J Immunol Baltim. Md 1950. 2015; 194:113-24.

21. Sakaguchi S, Vignali DAA, Rudensky AY, Niec RE, Waldmann H. The plasticity and stability of regulatory T cells. Nat Rev Immunol. 2013; 13:461-7. 
22. van der Net JB, Bushell A, Wood KJ, Harden PN. Regulatory T cells: first steps of clinical application in solid organ transplantation. Transpl Int. 2015; 29:3-11.

23. Trzonkowski P, Szaryńska M, Myśliwska J, Myśliwski A. Ex vivo expansion of CD4(+)CD25(+) T regulatory cells for immunosuppressive therapy. Cytom Part J Int Soc Anal Cytol. 2009; 75:175-88.

24. Putnam AL, Brusko TM, Lee MR, Liu W, Szot GL, Ghosh T, Atkinson MA, Bluestone JA. Expansion of human regulatory T-cells from patients with type 1 diabetes. Diabetes. 2009; 58:652-62.

25. Hoffmann P, Eder R, Boeld TJ, Doser K, Piseshka B, Andreesen R, Edinger $M$. Only the CD45RA+ subpopulation of $\mathrm{CD} 4+\mathrm{CD} 25$ high $\mathrm{T}$ cells gives rise to homogeneous regulatory $\mathrm{T}$-cell lines upon in vitro expansion. Blood. 2006; 108:4260-7.

26. Marek N, Bieniaszewska M, Krzystyniak A, Juścińska J, Myśliwska J, Witkowski P, Hellmann A, Trzonkowski P. The time is crucial for ex vivo expansion of T regulatory cells for therapy. Cell Transplant. 2011; 20:1747-58.

27. Di Ianni M, Del Papa B, Zei T, Iacucci Ostini R, Cecchini D, Cantelmi MG, Baldoni S, Sportoletti P, Cavalli L, Carotti A, Pierini A, Falini B, Martelli MF, et al. T regulatory cell separation for clinical application. Transfus. Apher. Sci. Off. J. World Apher. Assoc Off J Eur Soc. Haemapheresis. 2012; 47:213-6.

28. Theil A, Tuve S, Oelschlägel U, Maiwald A, Döhler D, Oßmann D, Zenkel A, Wilhelm C, Middeke JM, Shayegi N, Trautmann-Grill K, von Bonin M, Platzbecker U, et al. Adoptive transfer of allogeneic regulatory $\mathrm{T}$ cells into patients with chronic graft-versus-host disease. Cytotherapy. 2015; 17:473-86.

29. Guidance for Industry Current Good Tissue Practice (CGTP) and Additional Requirements for Manufacturers of Human Cells, Tissues, and Cellular and Tissue-Based Products (HCT/Ps). 2011.

30. Gołąb K, Krzystyniak A, Marek-Trzonkowska N, Misawa R, Wang LJ, Wang X, Cochet O, Tibudan M, Langa P, Millis JM, Trzonkowski P, Witkowski P. Impact of culture medium on CD4(+) CD25(high)CD127(lo/neg) Treg expansion for the purpose of clinical application. Int Immunopharmacol. 2013; 16:358-63.

31. Ermann J, Hoffmann P, Edinger M, Dutt S, Blankenberg FG, Higgins JP, Negrin RS, Fathman CG, Strober S. Only the CD62L+ subpopulation of CD4+CD25+ regulatory $\mathrm{T}$ cells protects from lethal acute GVHD. Blood. 2005; 105:2220-6.

32. Fu S, Yopp AC, Mao X, Chen D, Zhang N, Chen D, Mao M, Ding Y, Bromberg JS. CD4+ CD25+ CD62+ T-regulatory cell subset has optimal suppressive and proliferative potential. Am. J. Transplant. Off. J. Am. Soc. Transplant Am Soc Transpl Surg. 2004; 4:65-78.

33. Miyara M, Yoshioka Y, Kitoh A, Shima T, Wing K, Niwa A, Parizot C, Taflin C, Heike T, Valeyre D, Mathian A,
Nakahata T, Yamaguchi T, et al. Functional delineation and differentiation dynamics of human CD4+ T cells expressing the FoxP3 transcription factor. Immunity. 2009; 30:899-911.

34. Tang Q, Bluestone JA. Regulatory T-Cell Therapy in Transplantation: Moving to the Clinic. Cold Spring Harb Perspect Med. 2013; 3:a015552.

35. Tang Q, Lee K. Regulatory T-cell therapy for transplantation: how many cells do we need? Curr Opin Organ Transplant. 2012; 17:349-54.

36. Singer BD, King LS, D'Alessio FR. Regulatory T cells as immunotherapy. Front Immunol. 2014;5:46.

37. Lee K, Nguyen V, Lee K-M, Kang S-M, Tang Q. Attenuation of donor-reactive $\mathrm{T}$ cells allows effective control of allograft rejection using regulatory $\mathrm{T}$ cell therapy. Am J Transplant. 2014; 14:27-38.

38. Battaglia M, Stabilini A, Roncarolo M-G. Rapamycin selectively expands CD4+CD25+FoxP3+ regulatory T cells. Blood. 2005; 105:4743-8.

39. Delgoffe GM, Kole TP, Zheng Y, Zarek PE, Matthews KL, Xiao B, Worley PF, Kozma SC, Powell JD. The mTOR Kinase Differentially Regulates Effector and Regulatory $\mathrm{T}$ Cell Lineage Commitment. Immunity. 2009; 30:832-44.

40. Hippen KL, Merkel SC, Schirm DK, Sieben CM, Sumstad D, Kadidlo DM, McKenna DH, Bromberg JS, Levine BL, Riley JL, June CH, Scheinberg P, Douek DC, et al. Massive ex vivo expansion of human natural regulatory $\mathrm{T}$ cells $(\mathrm{T}(\mathrm{regs})$ ) with minimal loss of in vivo functional activity. Sci Transl Med. 2011; 3:83ra41.

41. McIntyre CA, McCord R, Vrane D. Decontamination of the BD FACSAria System Using the Prepare for Aseptic Sort Procedure - FacsariaII_Decontamination. BD Biosciences Application Note. 2010.

42. Hoffmann P, Eder R, Kunz-Schughart LA, Andreesen R, Edinger M. Large-scale in vitro expansion of polyclonal human CD4(+)CD25high regulatory T cells. Blood. 2004; 104:895-903.

43. Kaminitz A, Yolcu ES, Askenasy EM, Stein J, Yaniv I, Shirwan H, Askenasy N. Effector and Naturally Occurring Regulatory T Cells Display No Abnormalities in Activation Induced Cell Death in NOD Mice. PLOS ONE. 2011; 6:e21630.

44. Levine BL, Cotte J, Small CC, Carroll RG, Riley JL, Bernstein WB, Van Epps DE, Hardwick RA, June CH. Large-scale production of CD4 $+\mathrm{T}$ cells from HIV1-infected donors after CD3/CD28 costimulation. J Hematother. 1998; 7:437-48.

45. Guidance for FDA Reviewers and Sponsors: Content and Review of Chemistry, Manufacturing, and Control (CMC) Information for Human Somatic Cell Therapy Investigational New Drug Applications (INDs). 2008. 